\title{
From Talk to Experience: Transforming the Preservice Physics Methods Course
}

\author{
Tom Russell \\ Queen's University
}

Shawn M. Bullock

University of Ontario Institute of Technology

\begin{abstract}
This report of a collaborative self-study describes and interprets our pedagogical approach at the beginning of a preservice physics methods course and outlines the strategy that we used to create a context for productive learning. We focus on our attempt to engage teacher candidates in dialogue about learning physics and learning to teach physics by engaging them in brief teaching experiences in the first month of a preservice teacher education program, before the first practicum placement. Self-study methodologies are used to frame and reframe our perceptions of teaching and learning as we enacted a pedagogy of teacher education that was unfamiliar both to us and to our teacher candidates.
\end{abstract}

Keywords: self-study of teacher education practices, lesson study, teacher education, physics, curriculum methods

Tom Russell is a Professor of Education at Queen's University in Kingston, Ontario, where he teaches physics curriculum and methods in the B.Ed. program and action research in the M.Ed. program. His research focuses on reflective practice, professional learning from experience, and innovative teaching procedures. He is an editor of Studying Teacher Education (Routledge) and has published a number of chapters related to learning to teach and self-study of teacher education practices. Email: tom.russell@queensu.ca

Shawn Bullock is an Assistant Professor of Education at the University of Ontario Institute of Technology in Oshawa, Ontario, where he teaches physics and mathematics curriculum and methods in the B.Ed. program and adult education in the M.Ed. program. His research focuses on the epistemological problem of how we learn from experience with a particular emphasis on how problems of learning science, problems of learning to teach science, and problems of learning to teach using digital technologies interact with each other. Email: shawn.bullock@uoit.ca

Brock Education, Volume 20, No. 1, Fall 2010, 19-33

Brock Education, 20(1), 19-33 


\section{Introduction}

This study emerged from personal dissatisfaction with the natural tendency to talk over and around the experience gap that exists at the beginning of any preservice methods course. It is natural and comfortable to spend the first month of classes preparing teacher candidates for their first practicum by exploring teaching strategies, lesson planning templates, and classroom management techniques. Indeed, most teacher candidates come to preservice teacher education programs expecting such initial activities. It is also natural and comfortable to direct these explorations of preparatory topics in familiar ways that represent transmission rather than construction of knowledge. One problem with a transmissive approach resides in the fact that teacher educators have significant teaching experiences that teacher candidates do not. Despite our best intentions to prepare teacher candidates for the practicum, teacher educators are often perceived to be transmitting strategies and ideas in ways that are unconnected to candidates' personal experiences and that contradict the content being taught. The gap between theory and practice can be extended unintentionally by initial classes, generating relationships and expectations that may be difficult to change as candidates gain first-hand practicum experience.

The false dichotomy between theory and practice is unproductive for both teacher educators and teacher candidates (Loughran, 2006). To address this issue, we engaged teacher candidates in teaching experiences during the early weeks of a physics methods course so that we could also engage them in extended dialogue about shared experiences of teaching and learning. This article reports how we enacted our pedagogy of teacher education during the first month of the program, how we framed and reframed the problems that we encountered, and how we came to understand the process of learning to teach in important new ways.

\section{Theoretical Framework}

Darling-Hammond (2006, p. 35) identifies three challenges of learning to teach that we find helpful to focus our attention on the quality of teacher candidates' early learning about teaching:

1. The problem of the Apprenticeship of Observation: "Learning to teach requires new teachers to understand teaching in ways quite different from their own experience as students."

2. The problem of Enactment: "Learning to teach requires that new teachers not only learn to 'think like a teacher' but also to 'act like a teacher.",

3. The problem of Complexity: "Learning to teach requires new teachers to understand and respond to the dense and multifaceted nature of the classroom."

The problem of the apprenticeship of observation names the reality that teacher candidates have spent many years as students without access to the pedagogical thought processes of their teachers (Lortie, 1975). For teacher educators, the challenge is to help teacher candidates enact rather than consume educational experiences. This task is particularly challenging given that the effects of the apprenticeship of observation on learning to teach remain invisible to most teacher candidates, particularly when replicating the cultural routines and practices of education tends to feel like good teaching. In addition, teacher candidates often experience tensions between the tacit knowledge they gained through the apprenticeship of observation and their experiences at faculties of education, particularly during practicum placements. The knowledge and beliefs obtained from the apprenticeship of observation are not "always compatible with the educational 
hopes of teacher educators ... [or] with the educational hopes of individual students of teaching" (Loughran, 2006, p. 114). We believe that it is crucial for teacher educators to generate experiences in which teacher candidates can begin to confront the lessons they learned tacitly from their extended apprenticeships of observation while also thinking about how to enact pedagogies consistent with the kind of teacher they want to become.

Teacher candidates often have a vision of pedagogy that is more sophisticated than they are able to enact (Liston, Whitcomb, \& Borko, 2006). This disparity between intended and enacted pedagogy is often the source of considerable stress for teacher candidates and new teachers (Hammerness, 2006). The problem of enactment encompasses the difficulties of both thinking and acting like a teacher, particularly when teacher candidates' prior assumptions about teaching and learning remain unexamined. In addition to providing opportunities for teacher candidates to confront their prior assumptions, teacher educators need to ensure that they are not indirectly contributing to the problem of enactment by leaving their own pedagogies unexamined. In teacher education, how we teach sends a more powerful message than what we teach. We believe that one way to teach candidates how to think like a teacher is to describe and interpret our thinking as we enact pedagogies in their classroom.

Left unexamined, the prior assumptions that teacher candidates have as a result of their apprenticeships of observation lead to the problem of enactment, as teacher candidates confront the reality that enacting pedagogy as a teacher is not as easy as observing pedagogy as a student. Teacher candidates are also confronted with the problem of complexity as they attend to the multiple demands, goals and realities of classroom teaching. Although the assertion that both teachers' professional knowledge and the process of learning to teach are complex is almost unquestioned in the teacher education literature, we join Loughran (2006, p. 31) in wondering how teacher educators can be "sensitive to the problematic" aspects of teaching. One of the major challenges of the problem of complexity is "avoiding the urge to seek a simple solution to a complex problem" (Loughran, p. 31), particularly as teacher educators work to help teacher candidates accept more responsibility for their own professional learning.

Sarason's (1996) concept of a context of productive learning helped us to address explicitly the problem of complexity in teacher education. A context of productive learning has three major features:

1. The teacher recognizes and respects the individuality of the learner.

2. The teacher knows the subject matter well enough to know when or where the learner may have difficulty.

3. The teacher is always seeking ways to stimulate and reinforce the learner's wanting to learn and do more. (Sarason, 1999, p. 143)

The third feature is particularly relevant to this study. Teacher candidates arrive at our preservice teacher education program understandably anxious to begin their practicum. Rather than focusing on the practicum as a place where candidates can apply knowledge learned in September, we chose to disturb that familiar theory-into-practice perspective by creating a context of productive learning founded on teaching experiences in the methods course. Through a discourse based on shared experiences of teaching and learning physics, we sought to stimulate and reinforce teacher candidates' desire to construct professional knowledge from teaching and learning experiences within the methods course.

The multiple interactions among teachers, learners, and experiences in a context of productive learning led us to Segall's (2002) frame of reading teacher education as text. According to Segall, the process of learning to teach is itself a text with deeply encoded 
meanings and assumptions. The interpretation of that text depends on the researcher, as the text is constructed by the interaction between researcher and data. As an experienced and a beginning teacher educator, respectively, we reveal our prior assumptions and experiences as "reading positions" (Segall, 2002, p. 8) with which we author and authorize a text of teaching a preservice physics methods course. Our positions are neither neutral nor dispassionate as we address the challenges of learning to teach and of learning to teach teachers through a collaborative selfstudy of our pedagogy of teacher education.

\section{Modes of Inquiry and Data Sources}

The context for this self-study is a preservice physics methods classroom in a 1-year, post-degree B.Ed. program at Queen's University in Kingston, Ontario. The class met twice a week for $21 / 2$ hours per class for 7 weeks in the Fall Term and again in the Winter Term. As is typical for 1year B.Ed. programs, the coursework at the Faculty alternated with extended experiences in host schools for a practicum. During the year this study was conducted, candidates were on campus during the months of September, November, January, and April. The data reported in this study were collected in September of that year.

The authors enacted a new pedagogy at the start of the year by arranging for each teacher candidate to have an experience teaching a physics lesson to the entire class. We organized experiences of teaching physics for the class to examine critically together. We tried to address the problem of the apprenticeship of observation by helping teacher candidates to identify their default teaching strategies, most of which come from extended student experiences. Finally, we taught teacher candidates how to reflect on their practice by enacting pedagogy designed to engage critical discussion of enacted pedagogy rather than by simply telling students about the importance of reflective practice. This paper describes and interprets the successes and challenges that we encountered enacting a new pedagogy of teacher education. We use our critical friendship as a basis for framing, reframing, and challenging our assumptions and perceptions of how we teach teachers and of how teacher candidates learn in our classroom.

This self-study is guided by Bullough and Pinnegar (2001), particularly with respect to the tensions that we encountered as we examine our pedagogy of teacher education. We are also mindful of Berry's (2007) work on tensions as a conceptual framework because they grow "out of teacher educators' attempts to match goals for prospective teachers' learning with the needs and concerns expressed by prospective teachers for their own learning" (pp. 119-120). Our discussions focus on tensions between our epistemological knowledge of teaching and learning and our enacted practices, between the expectations of our program structure and our expectations of ourselves, and between the context in which we learn to teach teachers and the context that we work to create with our candidates. Through rich description of these tensions, we try to offer fresh perspectives on some of the familiar dilemmas of teacher education.

Data were gathered at the beginning of our preservice program in the first 4 weeks of the physics methods course. The data include transcripts of audio-recorded conversations between the authors, email correspondence, and personal journals. As participant-observer, Shawn kept a particularly detailed research journal in which he recorded his perceptions of classroom events and Tom's comments to the physics methods class. Quotations presented in this paper come from one of these three sources; quotations are attributed to one of the authors. The data were analyzed inductively and deductively using standard qualitative analysis techniques (Patton, 2002) with a view to authentically representing our lived experiences as teacher educators. 


\section{Using Lesson Study to Disturb Expectations}

Both teacher educators and teacher candidates carry sets of expectations for methods courses in September. Past experiences have indicated that candidates expect to be told what they need to know in order to succeed on their practicum. As teacher educators, we expected to meet a group of candidates who are anxious about their first practicum placement and unsure about the role of coursework at a Faculty of Education. We expected a significant amount of tension as we try to avoid simply telling our candidates how to teach. As Tom noted after our first class, "We are compelled to interact for 4 out of 14 weeks before candidates are allowed to go out [on practicum] and learn what they need to know." Segall's (2002) notion of disturbing practice was one important catalyst for reconsidering our expectations of ourselves during the month of September. We realized that we needed to disturb and disrupt our candidates' expectations of September's classes while simultaneously disturbing our own expectations of the role of teacher educators at the beginning of our program.

The ideas of lesson study (Stepanek, Appel, Leong, Mangan, \& Mitchell, 2007) seemed to offer a promising way to disturb the expectations surrounding our methods course. Lesson study has a rich history in Japan and there has been increasing interest in the potential power of adapting lesson study for North American classrooms in the past decade. The process of lesson study challenges teachers to plan, enact, and reflect upon a jointly planned series of lessons. Typically, the lesson is taught by one teacher while the other teachers observe. The group of teachers then meets at a later time to analyze the lesson and to identify ways in which the lesson might be improved.

We believed that lesson study could provide a structure for signalling that meaningful learning experiences can be co-created and analyzed within a teacher education course, while minimizing the tension associated with waiting for the teaching experiences to happen during the practicum. We asked teacher candidates to plan lessons in groups of four with each person teaching one lesson planned by the group. Tom taught the course, while Shawn was participantobserver and critical friend. Asking each teacher candidate to present part of a physics lesson required us to devote two-thirds of our class time in September to those lessons. This approach was unfamiliar to us and so we usually spent time after each class sharing our sense of the effects of lesson study on candidates' learning.

\section{Learning from Lesson Study}

Predict-Observe-Explain (POE) pedagogy (Baird \& Northfield, 1992) is a commonly used in science classrooms and science teacher education classrooms to elicit students' prior understandings about a particular concept. On one level, it might be thought of as a way to promote more interactions during the demonstrations often found in science classrooms. Students are asked to make (and sometimes justify) predictions about what will happen, record observations about what actually happens, and construct explanations about the observations together with peers and the teacher. Although there are many variations to how a POE might be conducted, Tom tends to use the POE as a way to create a low-risk environment and a commitment to exploring concepts rather than creating a climate where only the correct prediction is valued. Candidates are provided with a situation that is typically more challenging than it appears, with a view to demonstrating that a safe classroom environment is critical to 
encouraging people to explore potentially incorrect prior assumptions. On the first meeting of the class, Tom used two POE sequences to draw the candidates into dialogue about the effects of the POE strategy on their learning by asking several questions:

1. What did you notice about what it was like to be learning using the POE approach?

2. What features of your learning did you notice by virtue of my using POE to teach you?

3. Can we all agree that teachers who don't think about how they are teaching simply stand and deliver, transmitting or covering the curriculum?

4. Did anyone feel embarrassed during the POE?

5. What tends to make people feel embarrassed in a classroom setting?

Tom tried to set the stage for the risk-taking and collaboration that would be required by lesson study by establishing an environment where asking questions about pedagogy was encouraged, and not seem as threatening. He called attention to the fact that the POE activities yielded a variety of predictions and explanations, despite the fact that everyone in the class had significant post-secondary study of physics. The critical point of the exercise was to focus candidates' attention on pedagogy, rather than right answers.

Tom began the second class with a third POE in order to re-emphasize the importance of asking critical questions about pedagogy within a positive classroom environment. After the POE, candidates were organized into groups of four and sign up to teach a series of concepts from the electricity and magnetism units in the Ontario curriculum. Following the model of lesson study described earlier, each group was asked to collaboratively plan one 20-minute lesson that would be taught by a member of the group to the rest of the physics class. After the first round of lessons, each group would be given the opportunity to meet and analyse their lesson in light of the comments provided by the other members of the class. Then during the second round of lessons, another person from each group would teach the modified lesson to the entire class and highlight the changes that were made.

Tom acknowledged the inherent difficulty associated with teaching a lesson to peers and tried to focus candidates' attention on the importance of discussing the effects the pedagogical approaches used by their peers had on their learning:

One of the things that is going to be really important is that everyone is going to feel a little uncomfortable when they present 20 minutes at the front. ... We are going to be good students because we are going to be listening to the learning effects that the teaching has on us. We are never going to criticize one another in terms of "Do $\mathrm{x}$ instead of y." We are going to develop a team atmosphere, saying things like "Maybe if you did it this way, you might have this kind of learning effect."

In keeping with the theme of establishing an atmosphere of trust early in the year, Tom admitted to the candidates that using lesson study in the physics methods course was a novel approach. He offered the following explanation for devoting so much time to creating in-class teaching experiences:

I am pretty sure that this is a different tack from your other curriculum course. Some of you might feel like you're missing out. I've been in this building too many years to be offended if an associate teacher asks you to forget everything you learned here in 
September. Everything you are told here is likely to go down the drain on the first day [of practicum] in October. Focusing on how teaching is affecting learning is far more useful than 6000 tips on how to teach physics.

Tom's explanation indicated his belief that teacher candidates could not be expected to directly enact tips and tricks for physics teaching into the practicum experience. Instead, he believed that the time in the physics methods course would be better spent learning to talk meaningfully about shared teaching and learning experiences. By explicitly describing the reasons for engaging in lesson study, Tom showed how a teacher educator can explicitly model his or her practice and create links between practice and literature. Lunnenberg, Korthagen, and Swennen (2007) highlighted the importance of modelling by teacher educators to assist teacher candidates in reframing their understandings of pedagogy.

As per our usual practice, we met immediately following the class to compare our thoughts about how the course was unfolding. Tom's first comments about lesson study focused on how he set up the process and his initial reading of the candidates' reactions:

The issues around how I went into the lesson study were partly due to doing it for the first time. I wasn't unhappy with the way it came out. I actually felt an enormous amount of relief when I asked what they were making of things . . . and I got the comment [from a teacher candidate] that something different was going to happen in this class.

Tom also mentioned that he was pleased that he changed the focus of the next class into planning time for lesson study. In his notes, Shawn had also made of note of the importance of giving the candidates additional time for lesson study:

I think that giving more time for lesson study underscored your message of "We'll figure it out together as we go." I don't know what specifically made you make the decision, but there was certainly a palpable sense of relief-not that they didn't think they could do it, but just to have that time to sit with their group again. It was good that you had the opportunity to show that you are flexible by changing plans on the spot.

Our after-class discussion allowed us to think carefully about how Tom's introduction to lesson study was in line with his commitment to building trust in his classroom. Given the workload associated with a preservice teacher education program, a simple gesture such as providing inclass time to work on a group assignment could go a long way to developing a supportive classroom environment.

\section{Beginning Lesson-Study Presentations}

The lesson study presentations began during the fourth class of the semester. Before the first group presented, Tom urged candidates to be mindful of the instinctive tendency we have to tell teachers about better ways to teach, particularly in a teacher education environment. Tom hoped the reminder would encourage candidates to think about pedagogy in terms of teaching strategies and learning effects, rather than in terms of best practices to be implemented. Shawn recorded the following observation during the first presentation: 
The candidates were very polite and paid rapt attention to their peer who was brave enough to go first. One of the interesting things was that I could have predicted how the lesson would proceed. The candidate fell back on all the default practices of what he has seen teachers do time and time again. I could also have predicted the kind of assessment he would receive from an associate or a faculty liaison: voice control, pacing, timing, moving on quickly after the right answer was elicited. There was a demonstration so that it felt like a science class.

At the conclusion of the first lesson, Tom took the opportunity to call candidates' attention to the influence of the apprenticeship of observation by asking, "Where did he learn to do what he just did? Has he learned to teach that way in 10 days of classes?"

The candidates who did not present were given whiteboards and markers and asked to discuss the lesson in small groups and record their comments. After about 10 minutes of small group discussions, Tom collected the whiteboards and displayed them at the front of the class. Returning to the ideas that he introduced at the beginning of the class, Tom challenged the class by stating, "A lot of this reads like 'do X instead of Y.' What I am struggling with is that we haven't named the learning effects. . . Can we get better, individually and collectively, at naming the learning effect?"

\section{Difficulty Identifying Learning Effects}

The difficulty that teacher candidates had framing pedagogy as a relationship between teaching strategies and learning effects became more pronounced with each post-lesson class discussion. After the second presentation, for example, the candidates continued to make the kinds of comments they did after the first presentation, using the language of best practices. When Tom challenged the class to acknowledge that their comments still were not focused on learning effects, several teacher candidates argued that there was merely a semantic difference between making a statement such as "do X instead of Y" and making a statement such as "the teaching strategy affected my learning in X ways." Tom took a step back from the discussion and encouraged the candidates to talk more about the differences between teaching strategies and learning effects. From his position at the back of the classroom, Shawn was also challenged to think about learning effects, noting:

The semantic differences matter because [phrasing things in terms of learning effects] might serve as a reminder that people are affected by things in different ways. If pedagogy is a unified whole, is it a fair question to ask for the learning effects to be teased out from the teaching strategies, or is it more appropriate to ask for phrases with conjunctions? Saying "The learning effect was A because the teacher did B," is different from saying "The teacher should do $\mathrm{X}$ because $\mathrm{Y}$." Is the suggestion being made to conform to a perceived best practice, or is the suggestion being made to address a particular feature of the learning?

Shawn continued to think about the differences during the third candidate's lesson. Tom ended the class by asking candidates to anonymously record something that they learned about teaching and learning on an index card on their way out, a strategy he called a "ticket out of class." 
The difficulties that candidates were having with the post-lesson discussions dominated our post-class meetings. After a number of lessons and gentle reminders for Tom, we both felt that there was a qualitative difference in the kinds of comments the candidates made when they focused on the effects that particular teaching strategies had on the quality of their learning experience. The anonymous "tickets out of class" that candidates wrote revealed that many resisted the concept of a learning effect and felt that making suggestions pertaining to trying specific teaching strategies were more valuable. We agreed that it was important to be patient with the candidates' focus on trying to tell each other how to teach, rather than talking about how they were learning. We also agreed that candidates' preference to talk about teaching rather than learning seemed to us to be one important effect of the apprenticeship of observation. The culture of school emphasizes the overarching importance of the correct answer (Holt, 1964). Given that teacher candidates are usually students who were successful in the K-12 school system, it was somewhat unrealistic for us to expect candidates to embrace quickly discussions that were not focused on obtaining answers about the right ways to teach.

Our second problem of practice was brought to Tom's attention by a small group of teacher candidates just before the sixth class. This small group of candidates were upset with a perceived lack of participation from their peers during the lesson study process. Often, the candidate teaching the lesson would ask for some sort of input from the audience and no one would offer a response. Tom's response was to thank the candidates for bringing their concerns to him and to engage them in a bit more of a discussion about what they hoped for from the lesson study process. His other response was to ask the class to change their seating arrangement at the beginning of sixth class, in the hope that sitting with different people would encourage more discussion and participation. By the end of the sixth class, each group had presented its lessons once and thus it was time to give the groups a chance to modify their lesson for the second round of presentations. At the end of class, Tom made the problem raised earlier in the day explicit (without mentioning that a small group had spoken to him) by stating "it can feel like pulling teeth up here [in the role of teacher]" and encouraged candidates to pay attention to those situations.

During the post-observation discussion, Tom and Shawn spent a considerable amount of time discussing the difficulties some candidates were having with the process of lesson study. Shawn felt that the silent majority in the class were slipping into a default student mode and that perhaps candidates were discouraged by some of the reactions from their peers, given the amount of time that they put into planning their lessons. Shawn also noted that candidates, like many teachers, might have a tendency to say that there is a problem with the students, rather than with the lesson itself. In other words, it was possible that some of the lessons were not receiving much input from the class simply because they were not engaging. Tom had a different explanation for the difficulties experienced during the first round of lesson study. He brought the focus of the discussion back to the level of risk required by these short lesson-study presentations:

They are revealing a lot about themselves in this class that they are not revealing in other classes. There may be some reaction here that it is too much, too quickly. I realize that I am getting to see sides of them that I never would have otherwise, but I think that in the long run, there is a pay off. 


\section{Making Suggestions after Some Initial Teaching Experiences}

Partly in recognition of the fact that it was the halfway point in the lesson study process, and partly as a result of the conversation that we shared after the sixth class, Tom sent an email to the class later that evening. He included the following suggestions for candidates to consider when revising their lessons:

- We are not looking for perfection, just an improved approach that has reasons!

- Work whenever possible to move beyond traditional approaches (whatever that meansfamiliar, comfortable) to a plan that helps students be more active, more challenged, and more engaged in the lesson.

- Focus on a concept, and name your concept somewhere in your plan.

- Don't be afraid to stop at any point in the lesson, step out of your teacher role, and ask the class how they feel about particular aspects of what you are doing.

- Don't be afraid to call on people by name if you don't get responses; very few people have tried that so far, but that's always an option so it might be good to explore now.

Tom hoped to encourage candidates to think about the concerns we articulated during our postobservation discussions by framing the email as a series of suggestions rather than demands. The email was particularly powerful because Tom had made few comments about the candidates' lessons up until that point. It was particularly important that the email's comments focused on suggestions for improving the process, rather than on specific teaching strategies. We wanted to encourage candidates to think about how to improve the quality of their interactions with the class, and we agreed that the ways in which the lessons changed would be an important marker for thinking about what candidates learned from the experience.

The lessons that were taught during the first round were fairly traditional, teachercentred, and tended to follow the familiar pattern of introducing content before answering questions. During the second round of lessons, however, it quickly became apparent that candidates were trying to enact slightly riskier pedagogy, including a few demonstrations and POEs. There was more of an effort to engage the class in discussion, and Tom was more vocal about drawing candidates' attention to details such as font size on the overhead and the importance of admitting when one is lost in the middle of solving a problem. Tom also commented that everyone will initially teach as they were taught, not as they were told to teach. At the end of the seventh class, Tom reiterated that he was using lesson study in the hope "that there will be connections between experiences and preconceptions in this class and what happens when you come back."

One of the most significant challenges of enacting lesson study pedagogy was working out how to conclude the experience in a meaningful way that flowed naturally into the first practicum. The challenge was compounded by the enormous amount of time that was spent on the lesson study presentations and the fact that Tom worked hard to avoid making comments during the first round of lessons. After the final two lessons during the ninth and final class before practicum, Tom distributed a sheet of paper entitled "The Big Picture after 4 Weeks in Physics class" that contained four boxes in which candidates were invited to record new perspectives on teaching and learning: (a) from planning lessons in a group, (b) from watching others teach, (c) from presenting their own lesson, and (d) from working with equipment for teaching electromagnetism. 
After 15 minutes of independent writing, Tom encouraged the members of the class to share the thoughts they had recorded. One of the major themes in the discussion was the shared realization that, although the lessons were planned in groups, the way in which a particular lesson was enacted ultimately depended on the person at the front of the room. Candidates also felt that planning a lesson as a group was more time consuming than it would have been if they had planned lessons independently, particularly as they frequently had to negotiate several different approaches to teaching within the group. Tom said that he was particularly impressed that the groups got together on their own time to plan, without any prompting to do so. The members of the class felt that watching one another teach was a good way to learn different ways to think about physics content and how to present that content. A few candidates stated that they watched their peers with an interest in finding ideas for teaching particularly challenging topics, particularly those topics that they felt intimidated to teach during practicum. The class seemed to agree unanimously that there was no reason for concepts in electromagnetism to be presented as dryly as they often are at the high school and university levels.

One of the biggest insights raised during the discussion was the candidates' general consensus that knowing physics is not the same as knowing how to teach physics. We suspect that this insight was particularly strongly felt by the few candidates who seemed to rely on their ability to improvise during the first round of lessons. Tom took the opportunity at the end of class to explicitly develop the link between providing experiences in teaching via lesson study and providing experiences in physics via POEs:

I have always been fond of the idea of letting students have some experience with the stuff before you teach them the theory, and then let them go back and ask them how things are different now. We don't give them much of a sense of the before-and-after; perhaps that is part of the reason kids walk away without a good conceptual understanding of physics. There is an incredible sense in science teaching of tell first, explore later.

Ending the semester with a reminder that teaching tends to be built on a culture of telling was an important way to link the lesson study experiences to the experiences on the first day of the semester. First days of school at all levels are typically characterized by mundane exercises such as taking attendance, distributing textbooks, and discussing course outlines. The POE experience and its' emphasis on creating a classroom culture filled with exploratory, hypothetical talk was unlike what students typically encounter on the first day of class. The lesson study experiences built upon the culture of taking risks by providing an opportunity for the class to co-create and co-analyse a set of shared teaching experiences to discuss. Tom ended the semester by stating that lesson study pedagogy was a way of providing experiences that enacted his belief in an Explore First, Explain Later approach to science teaching and science teacher education.

\section{Conclusions}

This self-study arose from a shared desire to disturb the theory-into-practice assumptions underlying our preservice teacher education program. Lesson study served as a structure for generating shared teaching and learning experiences for candidates to discuss with their teacher educator, experiences that contrasted with the more familiar pattern of talking over and around 
the huge gap in teaching experience between teacher candidates and teacher educators. Enacting the lesson study experiences suggested two important considerations for teacher educators:

1. Teacher educators who share a problem in their practice with teacher candidates can create a unique opportunity to address the problem of enactment by explicitly modelling how an experienced teacher educator implements and critiques an unfamiliar pedagogical approach.

2. Methods courses are often characterized as the place where theory is learned so that it can be put into practice in the practicum. We believe that methods courses need not be artificially isolated from the crucible of practice in host schools. Although it is important to provide opportunities for candidates to make sense of their practicum experiences, it is equally important to provide meaningful opportunities for candidates to critically analyse the teaching and learning experiences that occur in their preservice courses.

Tom was explicit about both the purpose and pedagogy of lesson study during the month of September. He was open with candidates about his lack of experience with lesson study and regularly sought feedback about the process. He shared an authentic problem of practice with the candidates by framing lesson study as a way for him to avoid the culture of telling in teacher education. Most importantly, he tacitly introduced a disciplined approach to thinking about teaching by focusing on developing a vocabulary of teaching strategies and learning effects in place of the familiar rhetoric of best practices.

Initially, candidates found it difficult to articulate the effects that particular teaching strategies had on their learning. A part of this difficulty was probably due to a lifetime of learning how to behave like students and, by extension, act like teachers. Students in schools rarely, if ever, have opportunities to articulate the effects of particular pedagogies on their learning and thus it is not surprising that candidates struggled to identify direct relationships between teaching and learning. Throughout the lesson study experience, Tom provided at least one opportunity per class for candidates to confront and develop their understanding of teaching and learning by returning to the idea of learning effects.

The nature of teachers' professional knowledge is also relevant to this study. Our teacher candidates come from the disciplines of physics, engineering, and mathematics. An undergraduate education in these disciplines requires considerable attention to propositional knowledge. The discipline of teaching, as articulated by Loughran and Russell (2007), requires that teacher candidates attend closely to the problems of practice they encounter in their experiences. Attending to experience in a disciplined way is not natural and needs to be learned, yet teacher education programs seem to assume that it will happen spontaneously during practicum placements. Lesson study served as a way to bring experiences into a methods classroom in order to explicitly confront problems of practice.

Although many problems in physics are governed by overarching laws, solutions in teaching are messy and context-dependent. Tom concluded the pre-practicum classes by returning to his reasons for enacting the lesson-study pedagogy, but did not present lesson study as a solution to his problem of practice. Instead, he developed the idea of continuing to listen to candidates throughout the year in order to determine the potential long-term benefits of lesson study. 


\section{Did We Transform the Physics Methods Course?}

Some might argue that transform is too strong a word. Certainly, we cannot claim that the teacher candidates were transformed quickly into teachers, nor can we claim that they felt better prepared to begin to teach in a practicum school. We did transform our own thinking about what is possible and productive in the early weeks of a preservice methods course and the consequences of that transformation will become more apparent in subsequent physics methods courses that we will teach at our respective institutions. Meeting regularly after class helped us to clarify and challenge our reading positions, particularly with respect to the differences in our levels of experience in teacher education. For example, as a new teacher educator and participant observer, Shawn tended to focus on the details associated with the lesson study process, whereas Tom's experience in teacher education allowed him to make explicit connections from the lesson study pedagogy to his overall goals for the course. Our post-class conversations allowed us to explore the richness of both perspectives.

We both experienced significant tensions in enacting unfamiliar pedagogy and in responding productively to the reactions of teacher candidates to the idea of teaching a physics lesson to a group of peers. We believe that these tensions were essential for coming to appreciate the power of the experience, as the tensions ensured that teacher candidates confronted some of their prior assumptions about the concepts of physics and how physics might be taught. It was essential for us to attend to the developing relationships both with and among the teacher candidates as they were placed in the challenging situation of enacting their default pedagogies for an audience of peers. The process of lesson study gave meaning to enacting a pedagogy of teacher education that focuses on the relationship between teaching and learning and makes explicit the challenges of learning from experience.

We now see the early weeks of the methods course in new ways. We both believe that the apprenticeship of observation drives preservice candidates' expectations and initial teaching behaviours far more deeply and profoundly than most teacher education programs acknowledge. We believe that the assumptions, expectations and behaviours embedded in the experience of observing teachers for 16 or more years before attempting to teach can and should be challenged from the outset of a teacher education program. These challenges need to be more implicit than explicit, for there is little to be gained by telling candidates that they have already been shaped in ways that they do not understand.

We see these points as important elements of our own transformation that we will continue to explore in future physics methods courses that we teach:

1. An Explore First, Explain Later approach can be used productively in the earliest weeks of the course, so that candidates experience the approach before they try to understand its potential value as an approach to science teaching.

2. It is possible to begin to challenge implicitly the views of teaching and learning that have been taught unintentionally but thoroughly by the apprenticeship of observation.

3. Teacher educators have also been influenced profoundly by how they were taught in school and by how they learned to teach, and thus they too must explore and come to terms with their own apprenticeships of observation. 
To summarize, this collaborative self-study reminds us that the work of a teacher educator is more complex than naïve images of transmitting a knowledge base for teaching to beginners might suggest. The complexities and frustrations of enacting new practices can force us to confront the inevitable insight that beginning teachers face challenges (apprenticeship, enactment, complexity) far greater than traditional teacher education practices would suggest. As we work to help teacher candidates learn to direct their own development as teachers, examining and improving our own practices has become an increasingly important part of moving beyond teacher-centred talk toward learner-centred experience and creating experiential meaning for the knowledge base for teaching.

\section{Acknowledgement}

An earlier version of this article was presented at the 2008 meeting of the American Educational Research Association in New York. 


\section{References}

Baird, J. R., \& Northfield, J. R. (1992). Learning from the PEEL experience. Melbourne, Australia: Monash University Printery.

Berry, A. (2007). Reconceptualizing teacher educator knowledge as tensions: Exploring the tension between valuing and reconstructing experience. Studying Teacher Education, $3(2), 117-134$.

Bullough, R. V., Jr., \& Pinnegar, S. (2001). Guidelines for quality in autobiographical forms of self-study research. Educational Researcher, 30(3), 13-21.

Darling-Hammond, L. (2006). Powerful teacher education. San Francisco: Jossey-Bass.

Hammerness, K. (2006). Seeing through teachers' eyes: Professional ideals and classroom practices. New York: Teachers College Press.

Holt, J. (1964). How children fail. New York: Pitman Publishing Company.

Liston, D., Whitcomb, J., \& Borko, H. (2006). Too little or too much: Teacher preparation and the first years of teaching. Journal of Teacher Education, 57, 351-358.

Lortie, D. (1975). Schoolteacher: A sociological study. Chicago: University of Chicago Press.

Loughran, J. (2006). Developing a pedagogy of teacher education: Understanding teaching and learning about teaching. London: Routledge.

Loughran, J., \& Russell, T. (2007). Beginning to understand teaching as a discipline. Studying Teacher Education, 3, 217-227.

Lunenberg, M., Korthagen, F., \& Swennen, A. (2007). The teacher educator as a role model. Teaching and Teacher Education, 23, 586-601.

Patton, M. Q. (2002). Qualitative research and evaluation methods ( $3^{\text {rd }}$ ed.). Thousand Oaks, CA: Sage.

Sarason, S. B. (1996). Revisiting "The culture of the school and the problem of change." New York: Teachers College Press.

Sarason, S. B. (1999). Teaching as a performing art. New York: Teachers College Press.

Segall, A. (2002). Disturbing practice: Reading teacher education as text. New York: Peter Lang.

Stepanek, J., Appel, G., Leong, M., Mangan, M. T., \& Mitchell, M. (2007). Leading lesson study. Thousand Oaks, CA: Corwin Press. 